\title{
THEORETICAL EVALUATION AND OPTIMIZATION OF A CRYOGENIC TECHNOLOGY FOR CARBON DIOXIDE SEPARATION AND METHANE LIQUEFACTION FROM BIOGAS
}

\author{
Marco Spitoni $^{(a)}$, Mariano Pierantozzi ${ }^{(b)}$, Gabriele Comodi ${ }^{(a)}$, Fabio Polonara ${ }^{(a, c)}$ \\ Alessia Arteconi $^{(a)}$
}

\author{
(a) Dipartimento di Ingegneria Industriale e Scienze Matematiche, Università Politecnica delle Marche \\ via Brecce Bianche 1, 60131, Ancona, Italy \\ (b) SAAD, Università degli Studi di Camerino, Ascoli Piceno, 63100, Italy \\ (c) Consiglio Nazionale delle Ricerche (CNR): Construction Technologies Institute, Viale Lombardia 49, \\ 20098 (San Giuliano Milanese, (MI), Italy)
}

\begin{abstract}
The transport sector represents one of the major cause of air pollution and greenhouse gases emissions. For this reason, several measures have been taken: penalty and incentive schemes have been introduced worldwide to increase renewable energy sources and alternative fuels use. It is widely accepted that natural gas (NG) is a good alternative fuel, especially in its liquid form (LNG), and it can be produced using biogas as methane source to obtain renewable liquefied biogas (LBG). However raw biogas contains several impurities and it needs to be pre-treated. At present, several technologies allow biogas purification. In particular cryogenic separation represents a promising solution for simultaneous purification and liquefaction. It can achieve impurities removal and methane liquefaction by means of a single plant. In this work, a novel cryogenic separation process, based on $\mathrm{CO}_{2}$ cold recovery, is presented. The proposed plant is optimized and a sensitivity analysis is also performed. Results indicate that the proposed plant represents a valid option for LBG production. Indeed the specific energy consumption is $1.574 \mathrm{kWh} \mathrm{kg}^{-1}$ for a $\mathrm{CO}_{2}$ content in inlet biogas of $50 \%$. Furthermore the energy use and operative costs are compared with those of standard technologies and they result respectively $23 \%$ and $22 \%$ lower, taking into account the influence of $\mathrm{CO}_{2}$ as by-product.
\end{abstract}

Key words: biogas; natural gas; cryogenic separation; $\mathrm{LBG}$; LNG; $\mathrm{CO}_{2}$ recovery.

\section{INTRODUCTION}

Air pollution represents one of the major issues both for human health and climate changes. In particular the transport sector represents one of the main sources of air pollution, accounting for about $24 \%$ of global $\mathrm{CO}_{2}$ emissions (IEA, 2017). In 2016 the International Energy Agency estimated for this sector a share of about 50\% of the total nitrogen oxides $\left(\mathrm{NO}_{\mathrm{X}}\right)$ emissions and about $10 \%$ of the total particulate matter $\left(\mathrm{PM}_{2.5}\right)$ emissions, while the maritime transport has the largest share in $\mathrm{SO}_{\mathrm{x}}$ emissions (IEA, 2016). Policies and incentives have been introduced with the purpose of greenhouse gases (GHG) emissions reduction by decreasing fossil fuels utilization and increasing renewable fuels diffusion.

In this context, Natural Gas (NG) has been playing an important role. It can be efficiently used both in its compressed (CNG) and liquid (LNG) state for light and heavy-duty vehicles respectively (Spigarelli et al., 2016). LNG can actually substitute oil and diesel fuels in trucks (Hao et al., 2012) and carriers (Yoo, 2017) with a sensible reduction in GHG emissions. Furthermore biogas can be used as renewable feedstock source for NG. Since several countries introduced incentives schemes for biogas production and utilization, the number of existing biogas plants increased in the last decade and it is expected to increase more in the next years (Capodaglio et al., 2016). Biogas is produced by organic substrates decomposition. The process takes place in landfills or in specific anaerobic digesters (AD) by means of microorganisms, responsible for the digestion process. The result is a renewable fuel with high methane content. Biogas final composition is strictly 
related with the organic matter used in the process. Substances typically used to this purpose are mainly wastewaters, sewage sludge, organic fraction of municipal solid wastes, industrial wastes and manures. In Table 1 standard biogas, biomethane and natural gas compositions are reported. Although biogas contains a considerably high amount of methane, it is composed also of other substances, among them $\mathrm{H}_{2} \mathrm{O}, \mathrm{H}_{2} \mathrm{~S}$ and $\mathrm{CO}_{2}$. For this reason, since now biogas has been used mainly in cogeneration plants, even if with low efficiencies and corrosion problems for engines (Chutani et al., 2005; Schneidhofer et al. 2011; Maizonnasse et al., 2013). Instead, a purification process is required to use it as vehicle fuel. At present, biogas upgrading technologies for biomethane production are widely investigated (Hakawati et al., 2017). Miltner et al. (2017) reviewed novel techniques to achieve $\mathrm{H}_{2} \mathrm{~S}$ and $\mathrm{CO}_{2}$ removal from raw biogas. The work shows the economic and environmental performance of such solutions and their potential growth. Khan et al. (2017) investigated the utilization of biogas as bio-compressed natural gas (bio-CNG) and they provided specific recommendations for the necessary biogas upgrading.

Table 1. Molar composition of Biogas, Biomethane and Natural Gas (Sun et al., 2015; Faramawy et al. 2016).

\begin{tabular}{|c|c|c|c|c|c|}
\hline \multirow{2}{*}{ Constituents } & \multicolumn{5}{|c|}{ Composition [\% mol] } \\
\hline & Biogas (landfills) & Biogas (AD) & Biomethane & Wet NG & Considered Biogas \\
\hline $\mathrm{CH}_{4}$ & $35-65$ & $60-70$ & $\geq 95$ & 84.6 & $50-70$ \\
\hline $\mathrm{CO}_{2}$ & $15-40$ & $30-40$ & $\leq 3$ & $\leq 5$ & $30-50$ \\
\hline $\mathrm{H}_{2}$ & $0-3$ & 0 & 0 & 0 & 0 \\
\hline $\mathrm{H}_{2} \mathrm{O}$ & $1-5$ & $1-5$ & 0 & 0 & 0 \\
\hline $\mathrm{N}_{2}$ & 15 & 0.2 & 0 & $\leq 10$ & 0 \\
\hline $\mathrm{O}_{2}$ & 1 & 0 & $\leq 0.6$ & 0 & 0 \\
\hline $\mathrm{H}_{2} \mathrm{~S}$ & $0-0.001$ & $0-0.4$ & $\leq 0.4$ & $\leq 5$ & 0 \\
\hline $\mathrm{NH}_{3}$ & traces & 0.001 & 0 & 0 & 0 \\
\hline Heavy Carbons & 0 & 0 & 0 & 15.4 & 0 \\
\hline $\mathbf{L H V}\left[\mathrm{MJ} / \mathrm{Nm}^{3}\right]$ & 16 & 23 & 36.1 & 39 & 22 \\
\hline
\end{tabular}

Furthermore the utilization of biogas in its liquid form is gaining more and more interest, because of its high energy density. Liquid biogas (LBG) can be produced by means of a standard procedure composed of several steps: 1) biogas is first produced from landfills or anaerobic digestion; 2) an upgrading process purifies biogas to biomethane with high methane content; 3 ) a further purification is needed to achieve the high quality requirement for the liquefaction process (Faramawy et al., 2016); 4) finally, the liquefaction plant produces LBG. One of the first examples of LBG plant is in Sweden, it is based on an Air Liquid process and it is meant to supply vehicles and trucks with a renewable fuel (Lidkoping biogas, 2010). Although incentives have been introduced, costs for LBG production are still considerably high. Indeed, the upgrading process (mainly for $\mathrm{CO}_{2}$ removal) and the liquefaction process present high investment costs and are energy intensive (Johansson, 2008). As alternative to the process described above, $\mathrm{CO}_{2}$ removal and methane liquefaction can be performed in a single step through a cryogenic separation process. Consequently, it could lead to consistent cost reductions when the final product is expected in liquid form.

Tan et al. (2017) briefly reviewed cryogenic technologies for biogas upgrading and $\mathrm{CO}_{2}$ separation. They identified three main technologies, namely flash liquefaction system, distillation system and desublimation system. In the first system, biogas is first cooled and water removed, then it is subsequently flashed, compressed and further cooled down to obtain liquid $\mathrm{CO}_{2}$. In the second system a distillation column is used to remove and liquefy carbon dioxide. In the desublimation process, $\mathrm{CO}_{2}$ is removed during its phase change from vapor to solid inside a heat exchanger. The analysis showed that the flash technology is not able to achieve as high biomethane and final $\mathrm{CO}_{2}$ purity level as the other two techniques. Yousef et al. (2017) evaluated a novel distillation technology to remove $\mathrm{CO}_{2}$ from biogas to meet the specifications for pipeline transport or vehicle fuel. Although a good specific energy consumption of about $0.62 \mathrm{kWh} \cdot \mathrm{kg}^{-1}$ of produced biomethane is achieved, purity is not high enough for LBG production. Pentair Haffmans (2018) proposed a method for $\mathrm{CO}_{2}$ separation from biogas based on a combination of membrane technology and a cryogenic process: the carbon 
dioxide rich gas leaving the membranes is liquefied in order to recover $100 \%$ of the methane in the raw biogas. Chang et al. (2009) developed a novel technique for landfill gas upgrading and liquefaction using parallel heat exchangers for alternative switching. In their work a theoretical model was presented as well as experimental tests. Results demonstrated that the additional required heat exchange area for the desublimation process is not higher than $45 \%$ in comparison with pure methane heat exchangers. Jonsson and Westman (2011) presented an experimental study for $\mathrm{CO}_{2}$ desublimation by means of a plate heat exchanger to perform biogas upgrading. Pellegrini et al. (2017) evaluated three different technologies for biogas cryogenic upgrade, namely RyanHolmes process, dual pressure low-temperature distillation process and anti-sublimation process. The first and the second one are distillation-based processes in which $\mathrm{CO}_{2}$ is removed in its liquid form, the third one is based on the dry ice formation. Baccioli et al. (2018) compared a conventional plant for LBG production and a cryogenic plant based on a desublimation process. The latter technology was able to produce LBG with a competitive specific energy consumption equivalent to $1.45 \mathrm{kWh} \cdot \mathrm{kg}^{-1}$. Spitoni et al. (2017) investigated an upgrading technology for $\mathrm{CO}_{2}$ removal and biogas liquefaction based on PLNG (Pressurized LNG) technique using a desublimation process and able to achieve a final specific energy consumption of $1.44 \mathrm{kWh} \cdot \mathrm{kg}^{-1}$. A sensitivity analysis showed a specific energy consumption in a range of $1.284 \mathrm{kWh} \cdot \mathrm{kg}^{-1}-1.982 \mathrm{kWh} \cdot \mathrm{kg}^{-1}$ depending on $\mathrm{CO}_{2}$ content in inlet biogas. Indeed the carbon dioxide content and the possibility to recover it as by-product has a paramount importance for the feasibility of such cryogenic separation/liquefaction processes. Nachtmann et al. (2017) proposed an innovative low-temperature liquefaction system that separates carbon dioxide as dry ice and liquefies the remaining methane at normal pressure. By separating the $\mathrm{CO}_{2}$ as snow, the system allows to maintain the process continuous and recover the $\mathrm{CO}_{2}$ as by-product. Whereas an integrated process to separate and recover both liquid carbon dioxide and liquid methane is sold by the company Cryo Pur (2018). In their system carbon dioxide is separated through solidification in heat exchangers, then re-liquefied and recovered. This separation process is integrated with methane liquefaction, operated by means of external cooling and methane expansion.

In this work a novel cryogenic technology for biogas upgrading and liquefaction is presented. It includes an innovative cold load recovery and $\mathrm{CO}_{2}$ removal technique, here evaluated and discussed in detail. Indeed, although several studies evaluated LBG production by means of a desublimation process, the issue of solid carbon dioxide recovery process has generally been neglected. In fact, since the $\mathrm{CO}_{2}$ is stored into the heat exchanger during the liquefaction process, its accumulation during time must be considered and managed. Moreover, being at very low temperature, solid $\mathrm{CO}_{2}$ allows a not negligible cold energy recovery to increase the plant efficiency. Eventually the recovered carbon dioxide can be sold as by-product. In the literature survey above presented, indeed Nachtmann et al. (2017) deal with the operational issue of $\mathrm{CO}_{2}$ solidification. They propose to avoid the freezing of the heat exchangers so to have $\mathrm{CO}_{2}$ as snow and not as ice, while here it is collected as liquid and its cold reused in the plant. Instead in the Cryo Pur process the carbon dioxide is recovered by re-liquefaction in a heat exchanger through indirect contact with another carrier, while the proposed method recovers the $\mathrm{CO}_{2}$ liquid by means of direct contact with warmer and under pressure $\mathrm{CO}_{2}$. Furthermore the methane liquefaction cycle and its integration with the carbon dioxide separation process in the presented system are also innovative and allow to achieve a higher efficiency than other existing plants, as demonstrated by the results discussed in the next sections.

\section{METHODOLOGY}

This paper intends to present and evaluate a novel cryogenic separation plant able to achieve simultaneous purification and liquefaction of biogas. Given that $\mathrm{H}_{2} \mathrm{O}$ and $\mathrm{H}_{2} \mathrm{~S}$ can be removed easily beforehand from biogas with standard and low-cost processes (Muñoz et al., 2015), the cryogenic plant is intended solely for $\mathrm{CO}_{2}$ removal and $\mathrm{CH}_{4}$ liquefaction and from now on the term biogas is referred to a mixture uniquely of methane and carbon dioxide. In this section a thermodynamic analysis of the theoretical operating conditions for the proposed technology is performed. Being the aim of the present system the simultaneous separation of $\mathrm{CO}_{2}$ and production of LBG, cold load recovery as well as $\mathrm{L}_{-} \mathrm{CO}_{2}$ (liquid carbon dioxide) recovery systems are integrated in the plant. An optimization analysis is carried out in order to find the optimum setting of the plant. 
Results from the optimization process are post-processed in order to determine the most influencing input variables. Furthermore, considering the optimized plant, a sensitive analysis to quantify the impact of such variables on the plant performance is also presented. Eventually the cryogenic separation technology is then compared with the state of the art technologies to produce LBG.

\subsection{Thermodynamic analysis of the desublimation process}

In order to maximize $\mathrm{CH}_{4}$ content into the final product, $\mathrm{CH}_{4}-\mathrm{CO}_{2}$ liquid-vapor formation during the cryogenic process must be avoided. In fact, in this case, a considerable amount of methane would be mixed with carbon dioxide in both liquid and vapor form. If this occurs, $\mathrm{CO}_{2}$ removal process is more complex, requiring liquid-vapor separators. In order to efficiently and continuously remove $\mathrm{CO}_{2}$, a gas-solid separation process is proposed, namely desublimation process. Figure 1 illustrates $\mathrm{CH}_{4}-\mathrm{CO}_{2}$ binary system phase diagram and the desublimation process for biogas with an initial $50 \% \mathrm{CO}_{2}$ content can be analyzed here (Zhang et al., 2011).

The starting point of the desublimation process (point A) must take place at a pressure lower than biogas triple point (purpled T-P point), because in this way when the cooling process occurs, the $\mathrm{CO}_{2}$ is solidified directly from its vapor state. However, too low operating pressure results in low biomethane final temperature and then higher final energy consumption. Therefore, depending on biogas composition, the operating pressure must be the highest possible pressure below the corresponding triple point, taking into account a safety margin.

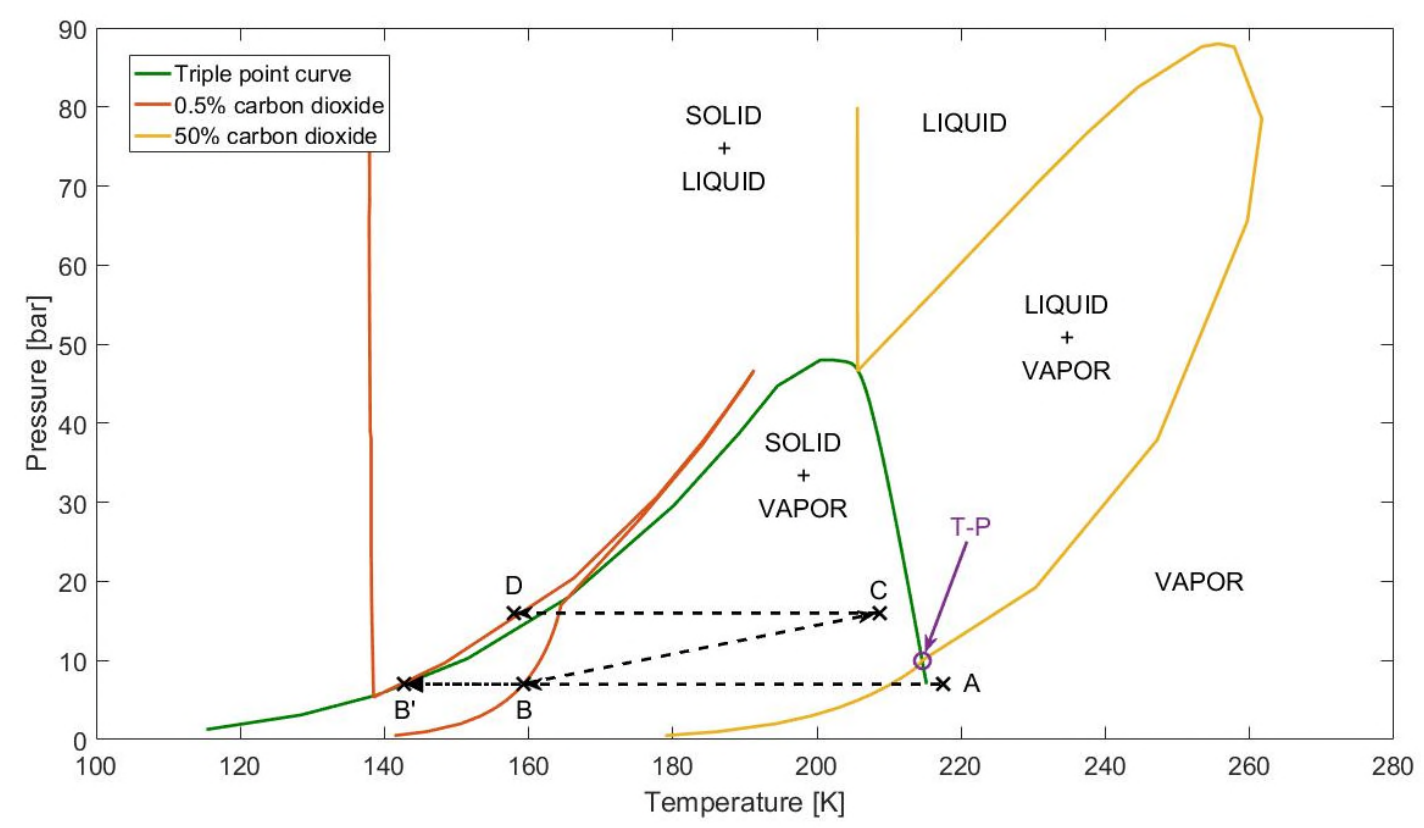

Figure 1. Phase diagram of $\mathrm{CH}_{4}-\mathrm{CO}_{2}$ binary system. Yellow and orange curves refer to mixtures with $50 \%$ of $\mathrm{CO}_{2}$ and $0.5 \%$ of $\mathrm{CO}_{2}$ respectively, while the green curve is the triple point interpolation curve. Purple arrow, T-P point, indicates the triple point of the mixture with $50 \%$ of $\mathrm{CO}_{2}$ with lowest pressure. A and B points represent respectively the initial and final conditions of the desublimation process. B-C and C-D paths are biomethane compression and liquefaction processes respectively. B' point represents the maximum achievable biomethane purity.

In detail, during the desublimation process biogas (at point A) is cooled down at constant pressure. Carbon dioxide is subsequently separated in the solid state, resulting to be $100 \%$ pure component (Xiong et al., 2015), while methane content becomes higher and higher. In order to achieve high purity biomethane, the temperature 
must be decreased as close as possible to the left side of the triple point interpolation curve. In fact, as already mentioned, the lower the final biomethane temperature, the higher amount of solid $\mathrm{CO}_{2}$ is separated. On the other hand, decreasing the final biomethane temperature considerably increases energy consumption due to higher cold load. Thus, a final $\mathrm{CO}_{2}$ content of $0.5 \%$ has been considered acceptable. Referring to Figure 1, the desublimation process ends at point $\mathrm{B}$, which corresponds to this condition. The minimum achievable $\mathrm{CO}_{2}$ content in biomethane would be obtained by continuing to cool down at constant pressure (going towards the left side of the triple point interpolation curve: point B' in Figure 1). In this case (point B') a minimum final $\mathrm{CO}_{2}$ content lower than $0.05 \%$ is theoretically achievable.

At the end of the desublimation process (point B), biomethane is still in its vapor form. In order to liquefy it, a compression (from point $\mathrm{B}$ to point $\mathrm{C}$ ) and a further cooling process (from point $\mathrm{C}$ to point $\mathrm{D}$ ) are required, thus LBG is obtained. Biomethane compression allows its liquefaction at higher temperatures, reducing energy requirements. Moreover it avoids plug issues due to the remaining carbon dioxide content, because solid carbon dioxide solubility in liquefied methane is increased with pressure (e.g. pressurized bio-gas, PLBG, is defined in a range of 15-20 bar (Hveding, 2010)). Figure 2 shows how S-CO $\mathrm{CO}_{2}$ (solid carbon dioxide) volume percentage solubility in LBG changes depending on its final temperature and pressure respectively (Shen et al., 2012): the higher is the final LBG pressure, the higher is the $\mathrm{S}-\mathrm{CO}_{2}$ solubility.

Considering a final $\mathrm{CO}_{2}$ content in biomethane not higher than $0.5 \%$, final LBG pressure (at point D) should always be higher than 8 bar, taking into account a safety margin (see Figure $2 \mathrm{~b}$ ). If the $\mathrm{CO}_{2}$ content would be decreased down to $0.05 \%$ in final LBG, this minimum pressure would become 1.3 bar. However, having such a low LBG pressure implies a low LBG temperature and higher energy consumptions. For this reason, the final LBG pressure should not be too low.
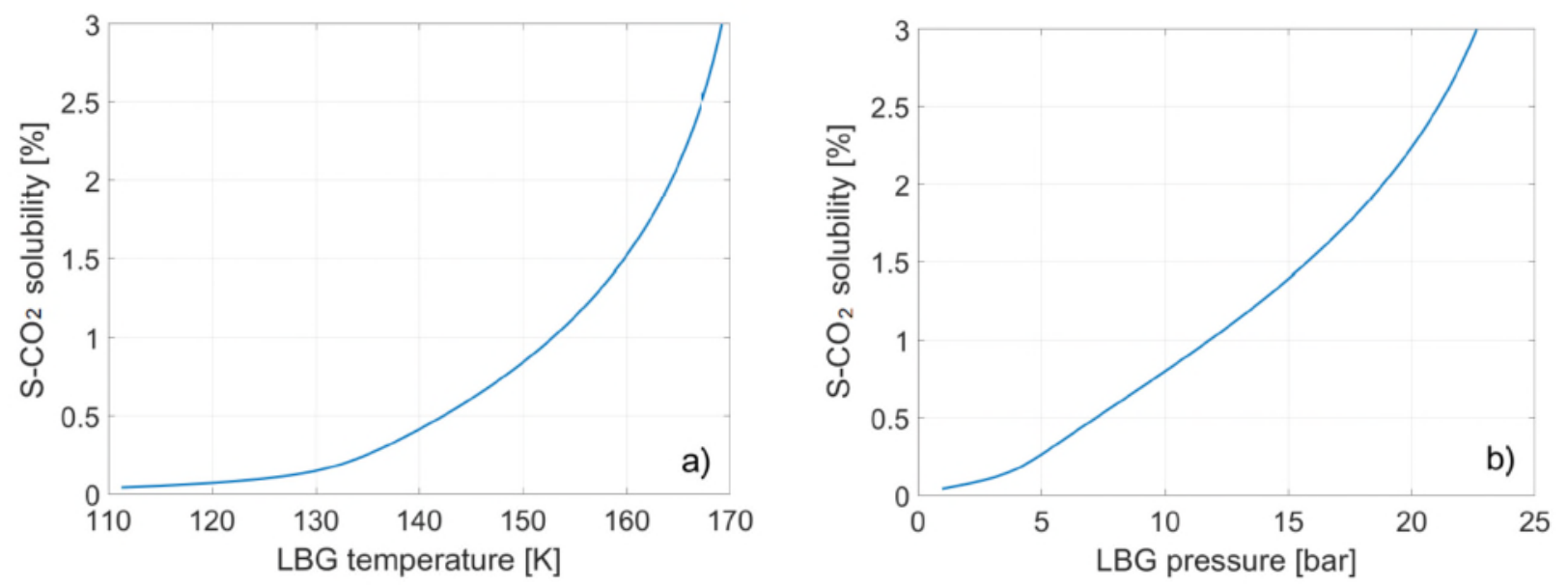

Figure 2. Solid $\mathrm{CO}_{2}$ solubility in LBG depending on its saturation temperature (a) and saturation pressure (b) respectively.

In the next section, more details regarding the gas-solid separation, as well as cold load recovery from S-CO for the proposed plant are provided.

\section{THE PROPOSED CRYOGENIC PROCESS}

\subsection{The process}

Figure 3 shows a schematic representation of the proposed plant. 


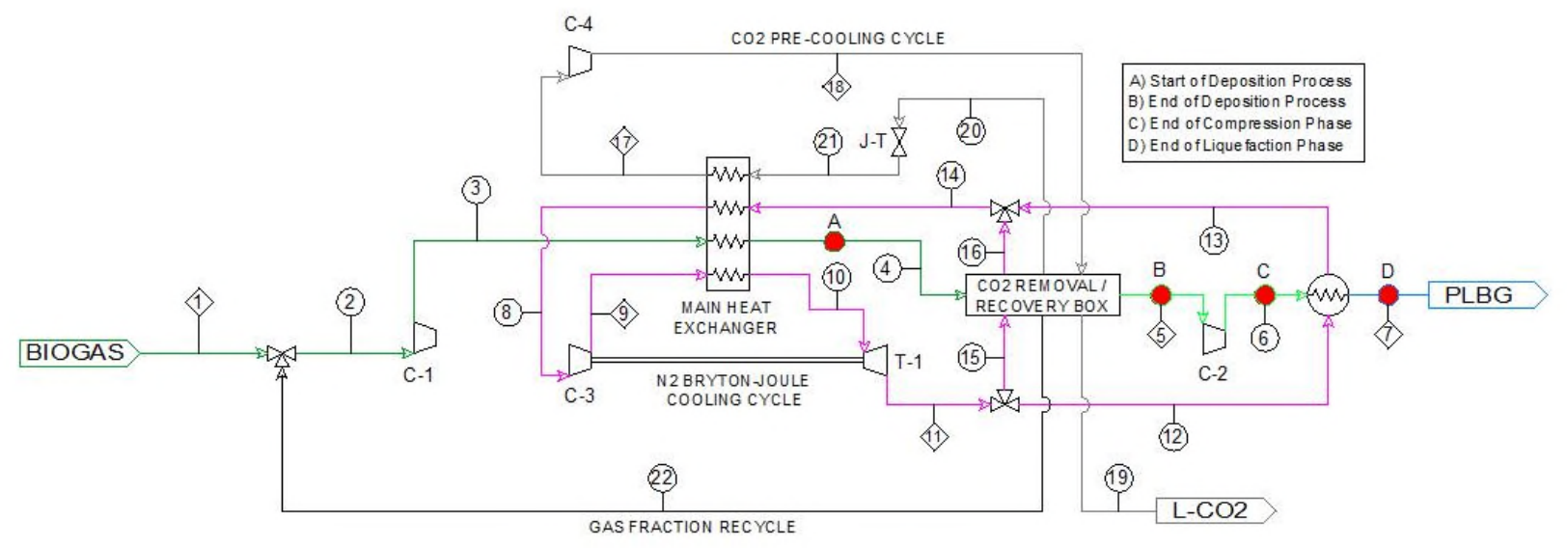

Figure 3. A schematic view of the proposed cryogenic separation-liquefaction process. A, B, C and D points refer to the thermodynamic conditions represented in Figure 1. The dark green, light green, blue, grey and purple lines indicate respectively biogas, biomethane, LBG, carbon dioxide and nitrogen streams. Numbers indicate specific conditions referred to the optimization process in Table 6.

After dehumidification and desulphurization pre-processes, biogas is sent to the plant with an initial pressure of 1 bar. Depending on its composition, it is compressed through C-1 up to the appropriate operating pressure (i.e. the starting pressure for the desublimation process, as discussed in section 2.1). Compressed biogas is sent to the main heat exchanger in which its temperature is decreased down to point A represented in Figure 1. Then, it flows into the $\mathrm{CO}_{2}$ removal and recovery box. Here, biogas is further cooled down to the final cooling temperature, depending on operating pressure and purity requirements. During the cooling process, desublimation of $\mathrm{CO}_{2}$ occurs and highly pure biomethane is obtained after this step. On the other hand, $\mathrm{CO}_{2}$ removal and recovery box allows also cooling load recovery and $\mathrm{L}-\mathrm{CO}_{2}$ production. More details regarding $\mathrm{CO}_{2}$ removal and recovery box are presented in the next section. Biomethane produced at this stage (point $\mathrm{B}$ in Figure 1) is then further compressed up to its final pressure and cooled down to the state of subcooled pressurized LBG (PLBG) ready to be stored (respectively points C and D in Figure 1).

The cooling process is composed of two main cycles. The first one is the pre-cooling cycle with carbon dioxide. After being compressed carbon dioxide enters into the $\mathrm{CO}_{2}$ removal and recovery box (point 18 in Figure 3) in which its temperature is decreased. After that, it is expanded into a Joule-Thompson valve, thus cooling energy is provided to main heat exchanger (point 21 in Figure 3). The second one is the cooling cycle based on the reversed $\mathrm{N}_{2}$ Bryton-Joule cycle. Nitrogen is firstly compressed and sent to the main heat exchanger in which its temperature is decreased (point 9 in Figure 3). Then it is sent into the turbo-expander where a considerable amount of energy is recovered to drive the compressor (C3). After that the flow is divided into two streams. The first one is responsible for the entire desublimation process (point 15). The second one is responsible for biomethane final liquefaction (point 12). Eventually, the two streams are mixed together and sent back to the main heat exchanger (point 14). Their remaining cooling load is used in order to cool down both inlet compressed biogas and nitrogen. Considering Figure 3, compressor units C-1, C-3 and C-4 are meant to be multi-stage air-cooled reciprocating compressors.

\subsection{Cold load and $\mathrm{L}-\mathrm{CO}_{2}$ recovery}

During the desublimation process, biogas cooling and $\mathrm{CH}_{4}$ enrichment happen simultaneously. Biogas flowing through the heat exchanger is cooled down, $\mathrm{S}-\mathrm{CO}_{2}$ is produced on the cold surface of the heat exchanger. Thus, a growing distributive frost layer is formed and it causes the reduction of the heat exchanger cross-section (Jonsson and Westman, 2011). In order to overcome this issue and to make the process continuous, a secondary heat exchanger is introduced. The $\mathrm{CO}_{2}$, used as refrigerant in the pre-cooling cycle, is the means to perform 
both cold load and $\mathrm{S}-\mathrm{CO}_{2}$ recovery. This is the main novelty introduced by the proposed process. Figure 4 shows the stages of the process.

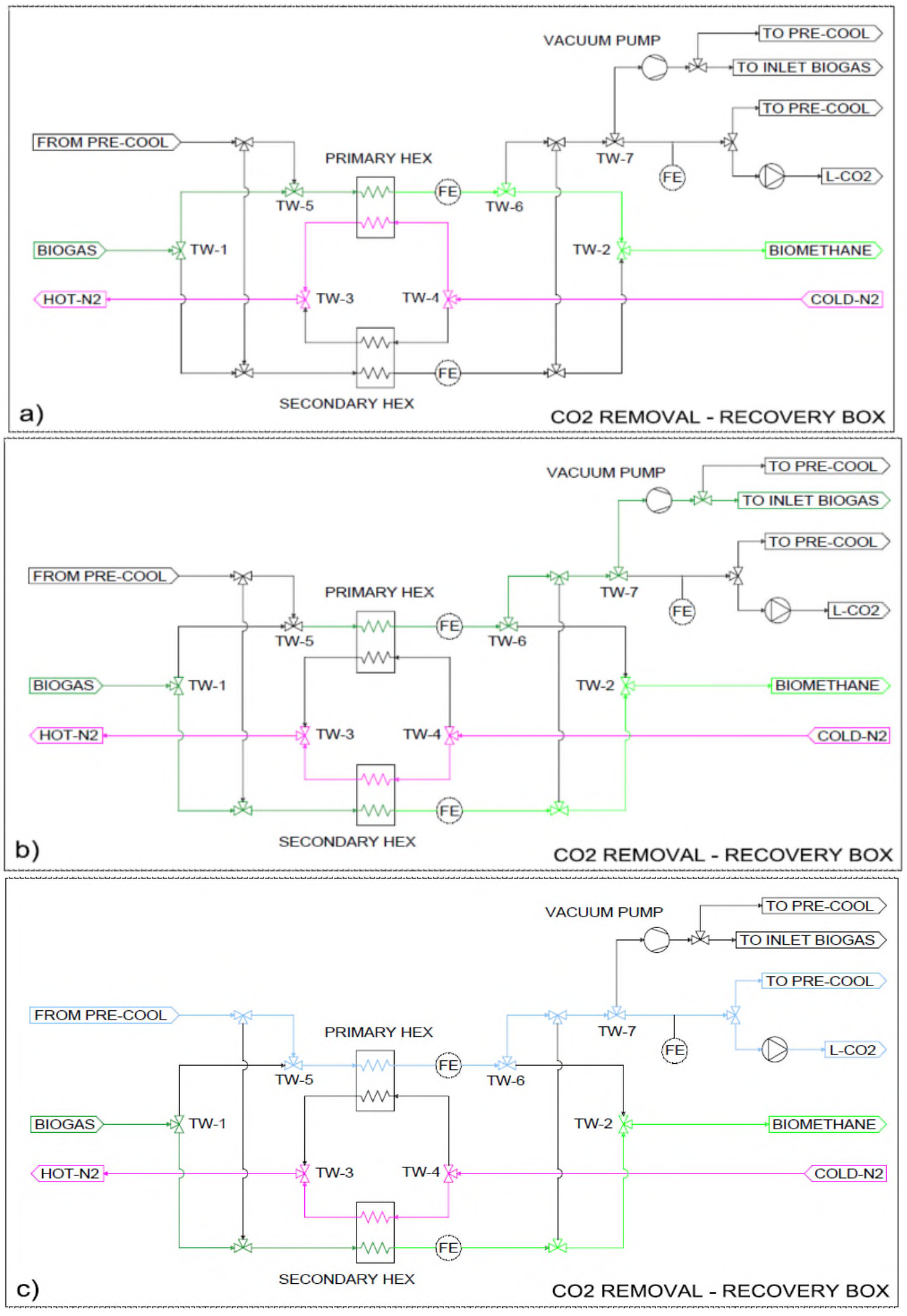




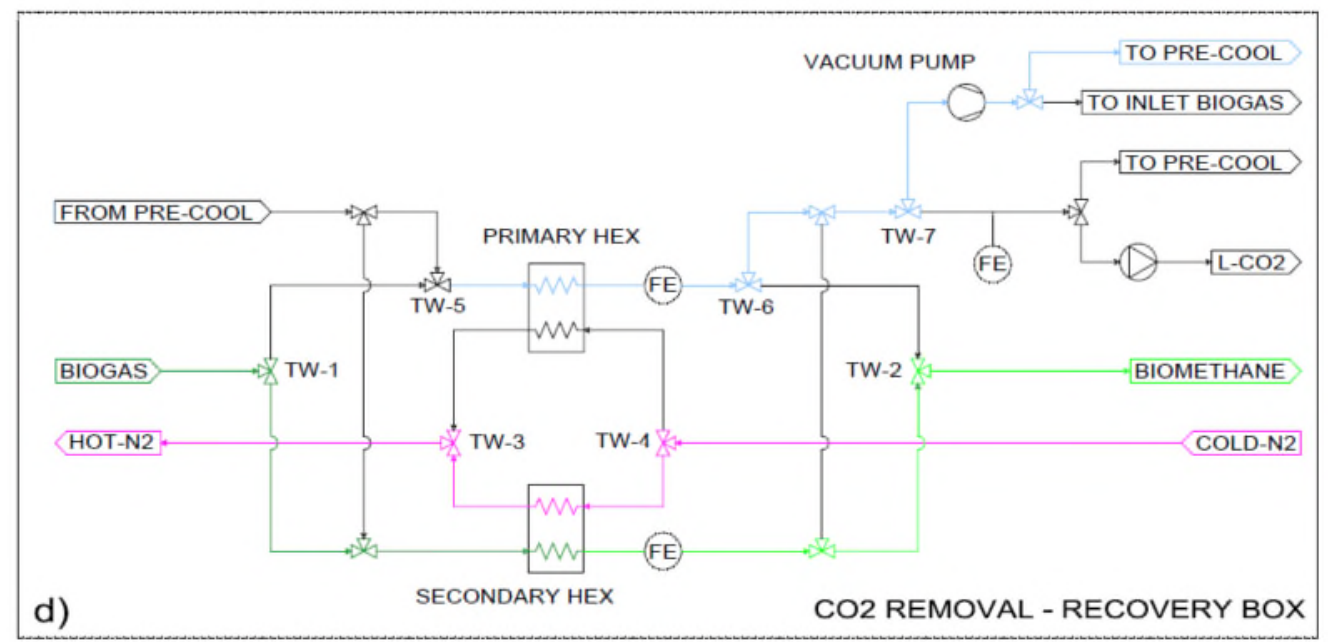

Figure 4. Schematic representation of the carbon dioxide and cold load recovery process occurring in the $\mathrm{CO}_{2}$ cold removal/recovery box. The dark green, light green, blue and purple lines indicate respectively biogas, biomethane, carbon dioxide and nitrogen streams.In Figure 4a the primary HEX is operating and a $\mathrm{CO}_{2}$ frost layer grows on its plates. In Figure $4 \mathrm{~b}$ the primary $\mathrm{HEX}$ is no longer able to perform desublimation of $\mathrm{CO}_{2}$ due to the frost layer thickness, thus biogas and nitrogen are sent to the secondary HEX to continue the desublimation process, while the vacuum pump removes remaining gas inside the primary HEX. In Figure 4c, carbon dioxide coming from the pre-cooling cycle is sent to the primary $\mathrm{HEX}$, thus solid $\mathrm{CO}_{2}$ is liquefied and both are sent back to the pre-cooling cycle and stored. In Figure 4d the recovery process ends and the remaining carbon dioxide is removed and sent to the precooling cycle.

Pre-cooled biogas, coming from the main heat exchanger (point 4 in Figure 3), is firstly sent to the primary heat exchanger (HEX) in counter current with cold nitrogen coming from the turbo-expander (point 15 in Figure 3). Thus, desublimation process occurs and biomethane with high purity level is produced while pure $\mathrm{S}-\mathrm{CO}_{2}$ is collected as a frost layer inside the primary HEX (Figure 4a). A flow sensor (FE) is responsible for the flow measurement so, when the flow decreases under a certain acceptable level, pre-cooled biogas as well as cold nitrogen are sent to the secondary HEX by means of three-way valves (TW-1, TW-2, TW-3 and TW4). This operation allows continuous desublimation and biomethane production processes. While secondary HEX is operating, primary HEX needs to be cleaned and $\mathrm{S}-\mathrm{CO}_{2}$ removed, because it is filled with solid carbon dioxide and enriched biogas in gaseous phase. Through three-way valves TW- 6 and TW-7, a vacuum pump removes remaining gaseous biogas to be re-circulated towards the inlet biogas stream (Figure 4b). Such mass flow is foreseen to be very low, thus this procedure does not affect inlet biogas composition. The vacuum pump is stopped when the flow is almost zero. At this point, primary HEX is connected with the pre-cooling cycle for cold load and $\mathrm{S}-\mathrm{CO}_{2}$ recovery. Using TW-5, an amount of pressurized $\mathrm{CO}_{2}$ flows through primary HEX, directly on the frozen layer. Consequently, the pressure level inside the primary HEX increases, while $\mathrm{S}-\mathrm{CO}_{2}$ is warmed up, changing its state to the liquid form (Figure 4c). The produced $\mathrm{L}_{-} \mathrm{CO}_{2}$ flow is then split into two streams. The first one is re-circulated to the pre-cooling cycle. The second one is pumped to higher pressure and stored in vessels, ready to be sold as by-product. As previously mentioned, produced $\mathrm{L}-\mathrm{CO}_{2}$ is $100 \%$ pure, allowing to sold it for alimentary purposes. Once $\mathrm{S}-\mathrm{CO}_{2}$ has been removed, TW-5 is closed and primary HEX is connected with the vacuum pump. Thus, remaining gaseous carbon dioxide is re-circulated to pre-cooling cycle (Figure 4d). At the end of the process, TW-1, TW-2, TW-3 and TW-4 restore the original situation. The secondary HEX is cleaned following the same procedure as in the primary HEX. By correctly sizing primary and secondary HEX, it is possible to guarantee the necessary exchanging area in order to make the process continuous.

Considering Figure 5 it is possible to better understand what happens during the $\mathrm{CO}_{2}$ and cold load recovery process (which refers to processes represented in Figures $4 \mathrm{a}$ and $4 \mathrm{~b}$ ). $\mathrm{S}-\mathrm{CO}_{2}$ collected on the primary HEX 
surface is represented by point I in the diagram. By removing remaining gaseous biogas, pressure is quickly decreased, thus frozen carbon dioxide begins to sublimate. Supposing this transformation as isotherm, point II in the diagram is reached, in which the vacuum pump flow rates is close to zero and the vacuum pump is stopped. $\mathrm{CO}_{2}$, coming from the pre-cooling cycle, flows and quickly increases the pressure inside the primary HEX and point III is reached. In this step $\mathrm{S}-\mathrm{CO}_{2}$ cools the gaseous $\mathrm{CO}_{2}$, thus the frozen layer is warmed up and liquid carbon dioxide occurs.

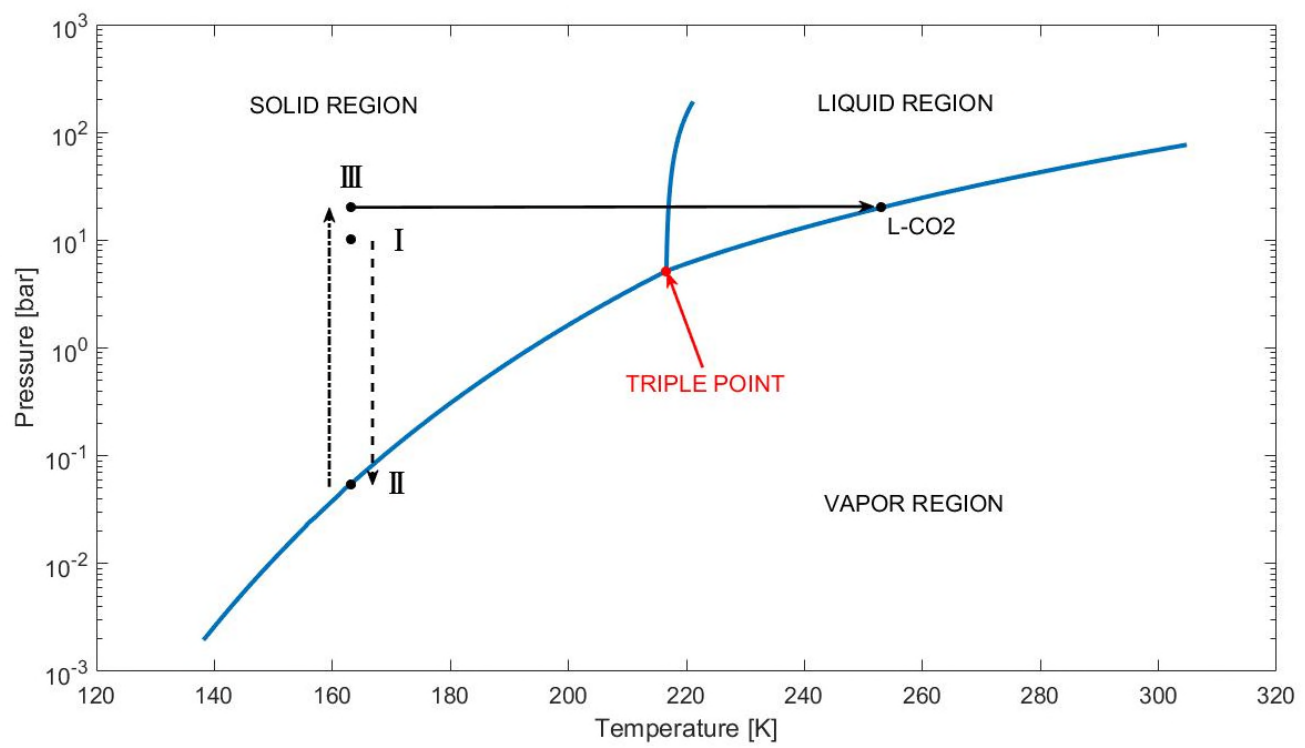

Figure 5. Phase diagram of pure $\mathrm{CO}_{2}$. Point I represents the solid $\mathrm{CO}_{2}$ inside the heat exchanger at the end of desublimation process. Point II represents solid $\mathrm{CO}_{2}$ conditions at the end of the vacuum pump operation. Point III represents the solid $\mathrm{CO}_{2}$ conditions when vapor $\mathrm{CO}_{2}$ from pre-cooling cycle flows into the heat exchanger.

\section{RESULTS AND DISCUSSION}

\subsection{Plant optimization}

A simulation model of the plant has been set up in order to evaluate and optimize the plant energy consumption. AspenHYSYS $®$ environment has been chosen as tool, it is indeed a software widely employed in the LNG sector (Gao et al., 2010, Yuan et al., 2014). Peng-Robinson equation of state is used to predict $\mathrm{CH}_{4}-\mathrm{CO}_{2}$ behaviour (Zhang et al., 2011, Riva et al., 2014). The software used for the optimization analysis is modeFrontier®, ESTECO. The objective function is the minimization of the specific energy consumption (i.e. the required energy in $\mathrm{kWh}$ to produce $1 \mathrm{~kg}$ of final product, in this case PLBG). The independent variables which mainly affect such energy consumption have been listed in Table 2 . The boundary limits of each variable have been set by considering feasible operating conditions of the plant and technical constraints (see Table 2).

Table 2. Input variables lower and upper bounds and step size considered in the optimization procedure. The numbers in brackets indicate the associated points (according to Figure 3 ) in the process where they are evaluated.

\begin{tabular}{lrrr}
\hline Parameters & Lower bound & Upper bound & Step size \\
\hline $\mathrm{N}_{2}$ high pressure (9) & $5 \mathrm{bar}$ & $80 \mathrm{bar}$ & $1 \mathrm{bar}$ \\
$\mathrm{N}_{2}$ low pressure (11) & $1 \mathrm{bar}$ & $36 \mathrm{bar}$ & $1 \mathrm{bar}$ \\
$\mathrm{CO}_{2}$ high pressure (18) & $10 \mathrm{bar}$ & $57 \mathrm{bar}$ & $1 \mathrm{bar}$ \\
$\mathrm{CO}_{2}$ low pressure (17) & $6 \mathrm{bar}$ & $20 \mathrm{bar}$ & $1 \mathrm{bar}$ \\
$\mathrm{PLBG}_{2}$ final pressure (5) & $15 \mathrm{bar}$ & $20 \mathrm{bar}$ & $0.5 \mathrm{bar}$ \\
$\mathrm{CO}_{2}$ content in biogas (1) & $30 \%[\mathrm{~mol}]$ & $50 \%[\mathrm{~mol}]$ & $1 \%[\mathrm{~mol}]$ \\
$\mathrm{CO}_{2}$ content in biomethane (5) & $0.1 \%[\mathrm{~mol}]$ & $0.5 \%[\mathrm{~mol}]$ & $0.1 \%[\mathrm{~mol}]$ \\
\hline
\end{tabular}


Nitrogen and carbon dioxide operating pressures are key parameters to determine the final energy consumption, as well as $\mathrm{CO}_{2}$ content in inlet biogas. The latter, in fact, strongly affects the plant operating conditions, as discussed in the following section. Biogas composition is a consequence of the anaerobic digestion process. More specifically, it mainly depends on biomass type and its content in produced biogas can be controlled. Since the proposed plant also integrates $\mathrm{CO}_{2}$ cold energy recovery, maximizing $\mathrm{CH}_{4}$ content in biogas could not necessarily results in a decreased specific energy consumption. By changing inlet biogas composition, the desublimation process operating pressure changes as well (see Section 2.1). Considering the abovementioned cold energy recovery process, the $\mathrm{CO}_{2}$ pre-cooling cycle high pressure level should be always higher than the triple point pressure of pure $\mathrm{CO}_{2}$. Thus, $\mathrm{S}-\mathrm{CO}_{2}$ liquefaction occurs instead of its sublimation. In order to avoid unfeasible designs, some constraints have been introduced (see Table 3).

Table 3. Considered constraints for the problem definition.

\begin{tabular}{lr}
\hline Constraint name & Condition \\
\hline $\mathrm{N}_{2}$ cooling cycle & $\mathrm{N}_{2}$ high pressure $>\mathrm{N}_{2}$ low pressure \\
$\mathrm{CO}_{2}$ pre-cooling cycle & $\mathrm{CO}_{2}$ high pressure $>\mathrm{CO}_{2}$ low pressure \\
Desublimation process pressure & PLBG final pressure $>$ Desublimation operative pressure \\
HEX minimum approach & $=5{ }^{\circ} \mathrm{C}$ \\
\hline
\end{tabular}

Once the problem is defined, DOE (design of experiments) and optimization algorithms are selected. DOE algorithms define a possible input variable set. Table 4 shows the selected algorithms and related setting values. A Random-Sobol-Incremental Space Filler sequence has been used for DOE definition, which guarantees a highly uniform input variable set. In DOE definition, the Random algorithm provides a certain number of feasible designs. Using those designs as a base, the Sobol and Incremental Space Filler algorithms are used subsequently to achieve a uniform DOE. The evolutionary strategy algorithm has been chosen for the optimization process.

Table 4. DOE matrix definition and optimization algorithms and parameters.

\begin{tabular}{lr}
\hline Algorithms & Number of DOE / iterations \\
\hline Random - DOE definition & 50 \\
Sobol - DOE definition & 100 \\
Incremental Space Filler (ISF) - DOE definition & 350 \\
Evolutionary Strategy (ES) - Optimization & 3499 \\
\hline
\end{tabular}

Table 5 summarizes the results of the optimization problem: the optimum value of the input variables (listed in Table 2) and the corresponding energy performance are reported. Table 6 , instead, shows the thermodynamic conditions in every point of the optimized plant.

Table 5. Optimum input variable set-point and corresponding results. The (i) and (o) indicates respectively input and output variables.

\begin{tabular}{|c|c|}
\hline Parameters & Optimal values \\
\hline $\mathrm{N}_{2}$ high pressure (i) & 45.25 bar \\
\hline $\mathrm{N}_{2}$ low pressure (i) & 16.25 bar \\
\hline $\mathrm{CO}_{2}$ high pressure (i) & 11 bar \\
\hline $\mathrm{CO}_{2}$ low pressure (i) & 6.5 bar \\
\hline PLBG final pressure (i) & $16.5 \mathrm{bar}$ \\
\hline $\mathrm{CO}_{2}$ biogas content (i) & $30 \%$ [mol] \\
\hline $\mathrm{CO}_{2}$ biomethane (i) & $0.4 \%[\mathrm{~mol}]$ \\
\hline Produced LBG (o) & $252.1 \mathrm{~kg} / \mathrm{h}$ \\
\hline Produced L-CO ${ }_{2}(\mathrm{o})$ & $287.9 \mathrm{~kg} / \mathrm{h}$ \\
\hline Required power (o) & $275.5 \mathrm{~kW}$ \\
\hline Specific Energy Consumption (o) & $1.093 \mathrm{kWh} / \mathrm{kg}$ \\
\hline
\end{tabular}


Table 6. Temperature and pressure in different points (see Figure 3) of the proposed optimized plant.

\begin{tabular}{cccccc}
\hline Point & Stream & Vapor fraction & Temperature $\left({ }^{\circ} \mathrm{C}\right)$ & Pressure $($ bar $)$ & Flow rate $(\mathrm{kg} / \mathrm{h})$ \\
\hline 1 & biogas & 1 & 35.0 & 1.0 & 308.2 \\
\hline 2 & biogas & 1 & 35.0 & 1.0 & 308.2 \\
\hline 3 & biogas & 1 & 40.0 & 15.5 & 313.2 \\
\hline 4 & biogas & 1 & -55.7 & 15.5 & 217.5 \\
\hline 5 & bio-CH & 1 & -107.8 & 15.5 & 165.3 \\
\hline 6 & bio-CH & 1 & -104.4 & 16.5 & 168.7 \\
\hline 7 & bio-CH & -114.4 & 16.5 & 158.8 \\
\hline 8 & $\mathrm{~N}_{2}$ & 1 & 37.0 & 16.3 & 310.1 \\
\hline 9 & $\mathrm{~N}_{2}$ & 1 & 40.0 & 45.3 & 313.2 \\
\hline 10 & $\mathrm{~N}_{2}$ & 1 & -87.3 & 45.3 & 185.8 \\
\hline 11 & $\mathrm{~N}_{2}$ & 1 & -130.2 & 16.3 & 143.0 \\
\hline 12 & $\mathrm{~N}_{2}$ & 1 & -130.2 & 16.3 & 143.0 \\
\hline 13 & $\mathrm{~N}_{2}$ & 1 & -113.7 & 16.3 & 159.5 \\
\hline 14 & $\mathrm{~N}_{2}$ & 1 & -99.4 & 16.3 & 173.7 \\
\hline 15 & $\mathrm{~N}_{2}$ & 1 & -130.2 & 16.3 & 143.0 \\
\hline 16 & $\mathrm{~N}_{2}$ & 1 & -61.7 & 16.3 & 211.4 \\
\hline 17 & $\mathrm{CO}_{2}$ & 1 & 35.0 & 6.5 & 308.2 \\
\hline 18 & $\mathrm{CO}_{2}$ & 1 & 40.0 & 11.0 & 313.2 \\
\hline 19 & $\mathrm{CO}_{2}$ & 0.455 & 22.0 & 60.0 & 295.1 \\
\hline 20 & $\mathrm{CO}_{2}$ & 0 & -42.3 & 11.0 & 230.8 \\
\hline 21 & $\mathrm{CO}_{2}$ & 0.045 & -50.3 & 6.5 & 222.8 \\
\hline Total Installed power [kW] & 335.42 & & & & \\
\hline Nitrogen Expander power $[\mathbf{k W}]$ & 59.87 & & & & \\
\hline
\end{tabular}

\subsection{Variables correlation analysis}

A correlation analysis has been carried out to evaluate how the variability of the input variables affect final results. In Figure 6, the parallel coordinate chart is shown. As it can be seen, each variable is represented by a vertical axis (coordinates), while the last one on the right side is associated with the objective function (the total energy consumption in this case). Each line represents a specific set of input variables with the corresponding specific energy consumption. The chart allows a better understanding of the variable range that actually gives the best final result. 


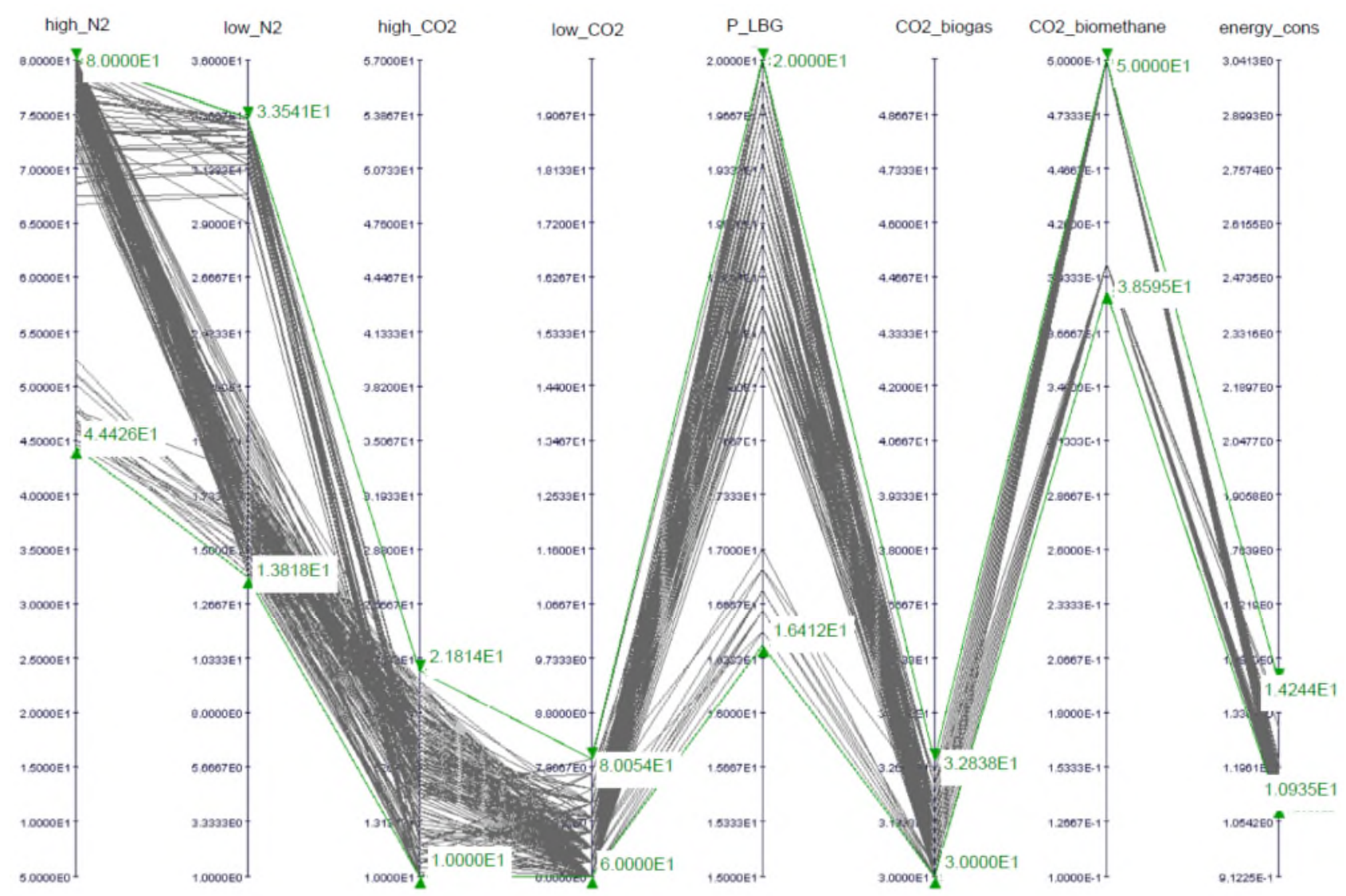

Figure 6. Parallel coordinates chart. Each grey line represents a considered plant configuration.

In Table 7 all the variable ranges related to a final specific energy consumption lower than $1.424 \mathrm{kWh} / \mathrm{kg}$ (specific energy consumption of the best traditional technology, see Table 10) are summarized.

Table 7. Input variable ranges from parallel coordinates chart analysis.

\begin{tabular}{lr}
\hline Parameters & Optimal ranges \\
\hline $\mathrm{N}_{2}$ high pressure & $(44.4-80) \mathrm{bar}$ \\
$\mathrm{N}_{2}$ low pressure & $(13.8-33.5) \mathrm{bar}$ \\
$\mathrm{CO}_{2}$ high pressure & $(10-21.8) \mathrm{bar}$ \\
$\mathrm{CO}_{2}$ low pressure & $(6-8) \mathrm{bar}$ \\
$\mathrm{PLBG}_{2}$ final pressure & $(16.4-20) \mathrm{bar}$ \\
$\mathrm{CO}_{2}$ biogas content & $(30-32.8) \%[\mathrm{~mol}]$ \\
$\mathrm{CO}_{2}$ biomethane & $(0.4-0.5) \%[\mathrm{~mol}]$ \\
Specific Energy Consumption & $(1.093-1.424) \mathrm{kWh} / \mathrm{kg}$ \\
\hline
\end{tabular}

Furthermore the Pearson correlation coefficient has been calculated to assess the correlation of every variable to the final energy consumption (Hall, 1999). Such coefficient expresses the relationship between input variables and objective function. The coefficient is a dimensionless number ranging from -1 to 1 , in which a positive value means that if associated variable increases, the objective function increases as well, while it decreases for negative values. If the coefficient is close to 0 it means that no significant correlation is found. In Figure 7, the result of such evaluation is reported. 


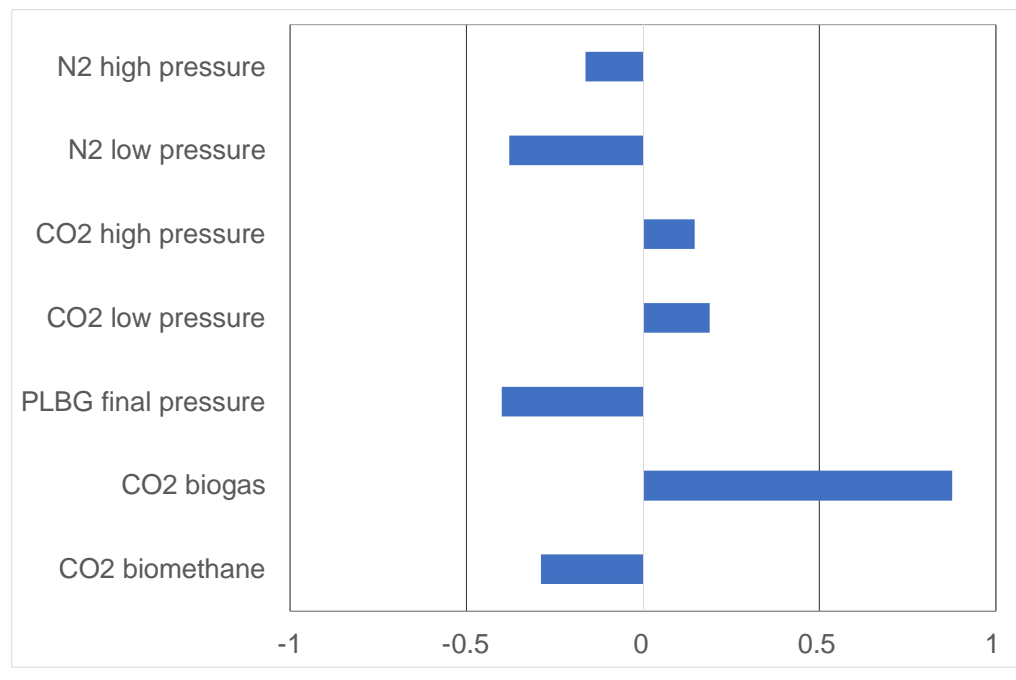

Figure 7. Pearson correlation coefficient analysis.

As it can be seen, inlet biogas composition, biomethane composition and PLBG pressure have great influence on the specific energy consumption of the proposed plant. Considering the inlet biogas composition, if inlet $\mathrm{CO}_{2}$ increases, specific energy consumption increases as well. This is mainly due to the fact that $\mathrm{CH}_{4}$ decreases, thus the required energy to produce $1 \mathrm{~kg}$ of PLBG, namely specific energy consumption, increases. Considering the final $\mathrm{CO}_{2}$ content in biomethane, instead, its increase causes a reduction of the specific energy consumption. The reason is linked with the desublimation process. In fact, if final carbon dioxide in produced biomethane is high, the final temperature involved in the desublimation process is increased, thus reducing the required cold load (Figure 1). Similarly, by increasing final PLBG pressure, specific energy consumption is decreased because liquid formation occurs at higher temperatures, thus the required cold load is reduced. The other important input variable is the nitrogen pressure in the low-pressure section of the reversed BraytonJoule cycle. This is a consequence of the expansion process through the cryogenic turbine. In fact, if the turbine discharging pressure is low, expanded nitrogen will be at low temperature as well, providing more cold energy load to the main heat exchanger. Regarding the $\mathrm{CO}_{2}$ pre-cooling cycle, it seems to have no great effect on final specific energy consumption being mainly responsible for biogas pre-cooling and $\mathrm{S}-\mathrm{CO}_{2}$ recovery.

The Pearson correlation coefficient is able to evaluate the influence of each input variable on the final objective function result. Regarding the mutual influence of combination of different input variables, a factor analysis gives more details about the input/output correlations. The factor analysis provides also information about the combination of input variables, instead of their single effect only. Table 8 provides more details about factor analysis results. It is evident that the specific energy consumption is mainly influenced by the final $\mathrm{CO}_{2}$ content in biomethane after the desublimation process. The second most influencing variable is the $\mathrm{CO}_{2}$ content in inlet biogas, while the third one is the combination of these two variables.

Table 8. Effects of factors on the specific energy consumption (with absolute effect higher than 0.2). Factors are intended to be the considered variables and their combinations (see Table 2).

\begin{tabular}{lr}
\hline Factors & Effect \\
\hline $\mathrm{CO}_{2}$ biomethane & -0.851 \\
$\mathrm{CO}_{2}$ biogas & 0.833 \\
$\mathrm{CO}_{2}$ biogas $* \mathrm{CO}_{2}$ biomethane & 0.810 \\
PLBG final pressure & -0.249 \\
PLBG final pressure $* \mathrm{CO}_{2}$ biomethane & -0.239 \\
PLBG final pressure $* \mathrm{CO}_{2}$ biogas & 0.201 \\
\hline
\end{tabular}




\subsection{Sensitivity analysis}

As already explained, inlet biogas composition is not a constant value (see Table 1). In fact, it could vary considerably depending on the biomass substrate used during the anaerobic digestion process. Moreover, the previous analysis has highlighted the strict correlation between $\mathrm{CO}_{2}$ content in inlet biogas and plant overall performance. Therefore, a sensitivity analysis has been performed in order to quantify the impact of $\mathrm{CO}_{2}$ content in inlet biogas on the optimized plant operating conditions (as determined in section 4.1). According to Table 1, such carbon dioxide content in inlet biogas can vary from a minimum value of $30 \%$ up to $50 \%$. Figures $8-10$ show the results of the sensitivity analysis in terms of specific energy consumption, biogas operating pressure, produced $\mathrm{LBG}$ and $\mathrm{L}-\mathrm{CO}_{2}$, costs and revenues.

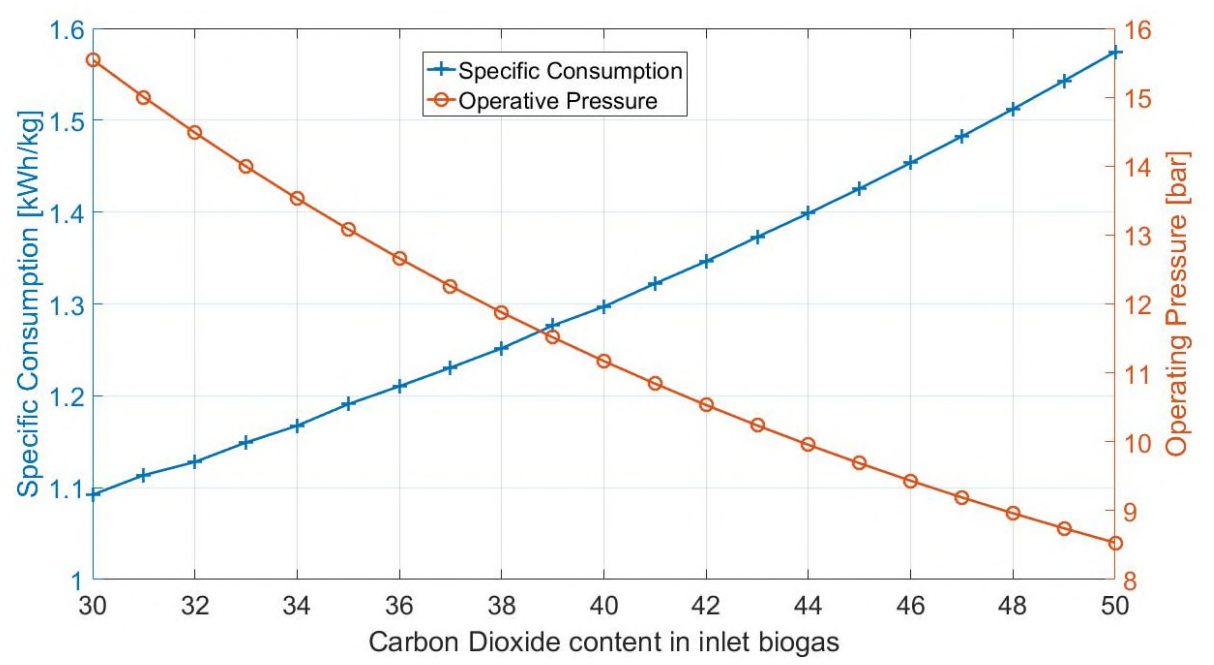

Figure 8. Specific consumption (per Kg of produced LBG) and operative pressure (after compressor $\mathrm{C}-1$ in Figure 3, at point $\mathrm{A}$ of the desublimation process) vs $\mathrm{CO}_{2}$ content in inlet biogas.

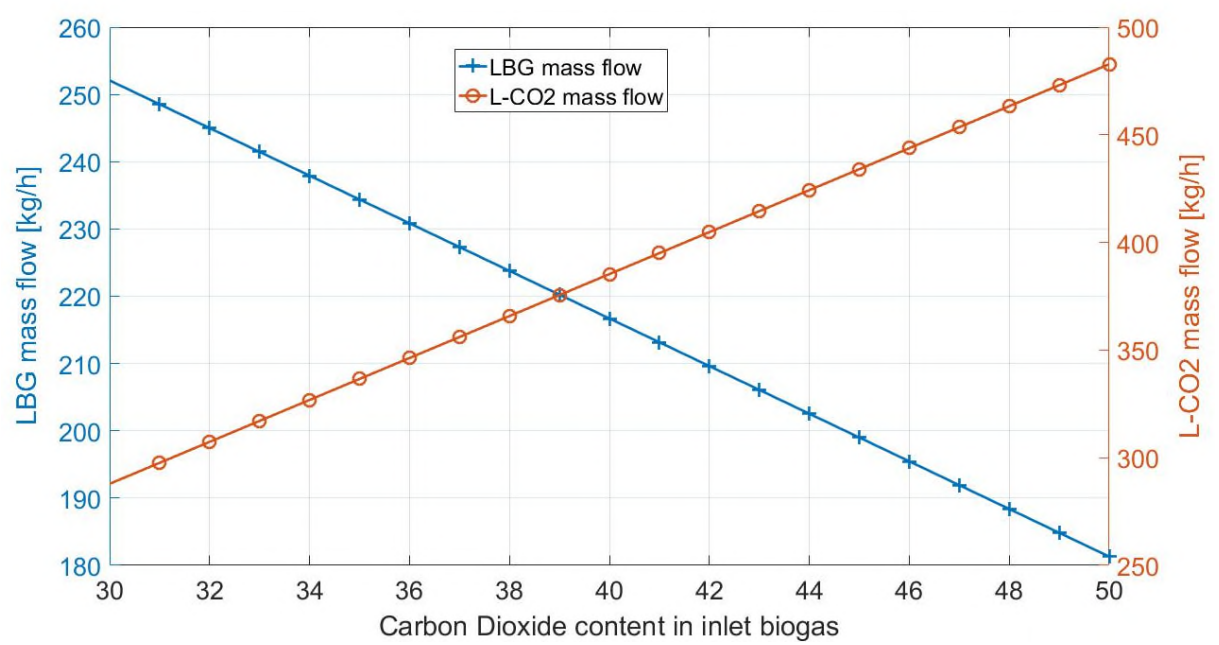

Figure 9. $\mathrm{LBG}$ and $\mathrm{L}-\mathrm{CO}_{2}$ produced mass flows vs $\mathrm{CO}_{2}$ content in inlet biogas. 


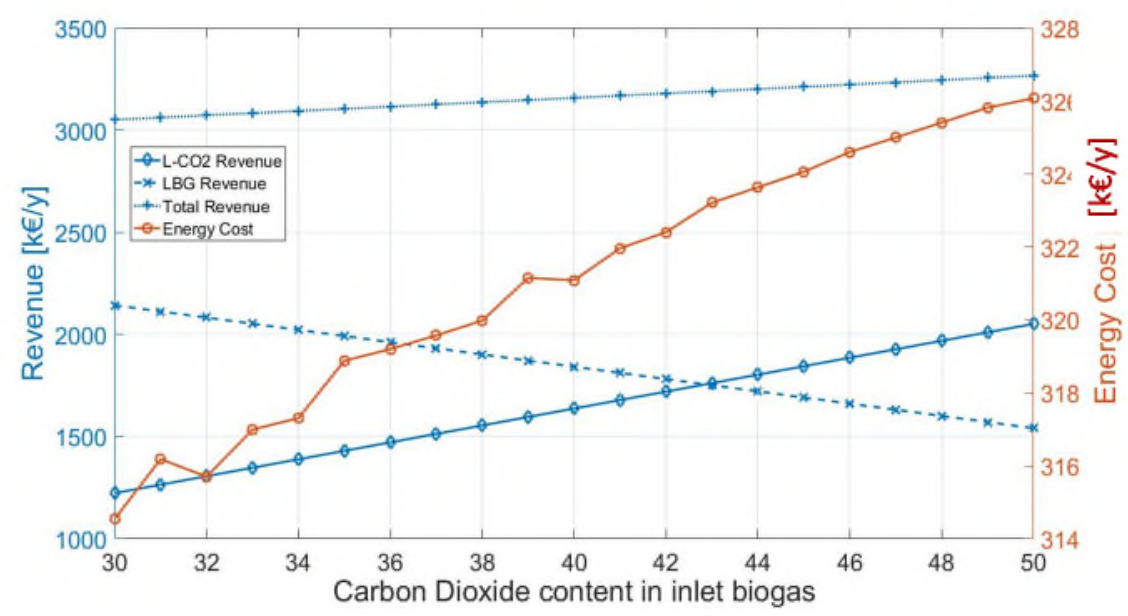

Figure 10. Annual costs and revenues vs $\mathrm{CO}_{2}$ content in inlet biogas (assessed assuming an electric energy cost of $0.1344 € \mathrm{kWh}^{-1}$, an LBG market price of $1 € \mathrm{~kg}^{-1}$ and an L-CO $\mathrm{O}_{2}$ Italian market price of $0.5 € \mathrm{~kg}^{-1}$, see section 4.4)

As expected, specific energy consumption (per kg of LBG produced) increases with the increased $\mathrm{CO}_{2}$ content in biogas (Figure 8). This is mainly due to the fact that by increasing the carbon dioxide content in inlet biogas, the total methane content is decreased. On the other hand, the operating biogas pressure during the desublimation process decreases when $\mathrm{CO}_{2}$ increases. Looking at Figure 1, it can be seen that the highest achievable operating pressure is a function of the carbon dioxide content in inlet biogas. The maximum allowable operating pressure is important in order to avoid liquid formation inside the main heat exchanger and to achieve higher heat transfer efficiency. Regarding LBG and L-CO $\mathrm{CO}_{2}$ production (Figure 9), they affect the economic performance of the plant and their trend is inversely influenced by $\mathrm{CO}_{2}$ content. Indeed, looking at Figure 10, although specific energy consumption is increased of about $31 \%$ by increasing $\mathrm{CO}_{2}$ content in biogas in the considered range, the total annual revenue is increased as well by $5.23 \%$. In fact, even if the mass flow rate of methane decreases of $21 \%$, the mass flow rate of carbon dioxide increases of $50 \%$ (Figure 9): by recovering and selling highly pure $\mathrm{CO}_{2}$ as a by-product, the total revenues tend to increase (Figure 10).

\subsection{Comparison with standard upgrading techniques}

The performance of the presented plant has been compared with those of conventional plants, where upgrading and liquefaction are performed in different stages, which are composed of (i) a conventional upgrading section, (ii) a further purification to achieve the necessary quality for liquefaction and (iii) a liquefaction plant (see section 1). The available conventional upgrading technologies are: pressurized water scrubbing (PWS), organic scrubber, chemical scrubber, pressure swing absorption (PSA), membrane and cryogenic separation. Then there are also other novel separation technologies under investigation, such as, for example, membrane absorption, which combines absorption and membrane separation (He et al., 2018), biological upgrading processes (Omar et al., 2018) or chemical absorption with efficient regeneration (Baena-Moreno et al., 2018). A detailed description of the most common traditional technologies can be found in the work of Tharän et al. (2014). Their state of the art efficiency and costs have been summarized in Table 9 (Muñoz et al., 2015; Johansson, 2008). Traditional cryogenic systems are intended uniquely for biogas upgrading and not for liquefaction. Moreover, a conventional desublimation plant for biogas upgrading and liquefaction has been also taken into account (as studied by Spitoni at al., 2017, where the plant is neither optimized nor including $\mathrm{CO}_{2}$ cold recovery). Molecular separation modules are typically used as further purification process to achieve a $\mathrm{CO}_{2}$ content lower than $50 \mathrm{ppm}$ (Faramawy et al., 2016), while as liquefaction technology a triple expansion Linde cycle (TP-L) has been considered a good option (Arteconi et al., 2015). In this analysis the costs for traditional separation technologies are taken from Brendeløkken (2016). For a fair comparison with literature 
data, a biogas flow rate of $500 \mathrm{Sm}^{3} \cdot \mathrm{h}^{-1}$ and a $\mathrm{CO}_{2}$ content in raw biogas of $40 \%$ are assumed. The operating conditions of the novel cryogenic plant are those obtained from the optimization process in section 4.1. An Italian electric energy cost of $0.1344 € \mathrm{kWh}^{-1}$ (Statistisches Bundesamt, 2018), an LBG market price of $1 € \mathrm{~kg}^{-}$ ${ }^{1}$ and an $\mathrm{L}_{-} \mathrm{CO}_{2}$ market price of $0.5 € \mathrm{~kg}^{-1}$ (for food industries - Italian market) have been used (Arteconi et al., 2015).

Table 10 summarizes specific production costs and energy consumption of the different plant configurations studied. In Figure 11 a cost-revenue analysis is also reported.

Table 9. State-of-the art costs and efficiencies of biogas upgrading technologies (Muñoz et al., 2015 Johansson, 2008).

\begin{tabular}{lrrrr}
\hline $\mathbf{C O}_{2}$ upgrading & $\begin{array}{r}\mathbf{C H}_{\mathbf{4}} \\
{[\%]}\end{array}$ & $\begin{array}{r}\mathbf{C H}_{\mathbf{4}} \text { not } \\
\text { recoverable } \\
{[\%]}\end{array}$ & $\begin{array}{r}\text { Costs } \\
{\left[\mathbf{E} / \mathbf{N m}^{\mathbf{3}}\right]}\end{array}$ & Requirements \\
& $>95$ & $<2$ & $0.11-0.15$ & $10-20 \mathrm{bar}$ \\
\hline PWS & $>96$ & 2 & $0.14-0.18$ & Solvents \\
Organic Scrubber & $>99$ & $<0.05$ & $0.16-0.17$ & Solvents / High temp. \\
Chemical Scrubber & $>96$ & 2 & $0.06-0.07$ & $4-10 \mathrm{bar}$ \\
PSA & $>96$ & 2 & $0.13-0.22$ & $20-40 \mathrm{bar}$ \\
Membrane* & 97 & & 0.4 & $80 \mathrm{bar} /-110^{\circ} \mathrm{C}$ \\
\hline
\end{tabular}

Table 10. Comparison between the proposed optimized plant and traditional technologies for LBG production.

\begin{tabular}{|c|c|c|c|c|c|}
\hline Upgrading technology & $\begin{array}{r}\text { Liquefaction } \\
\text { technology }\end{array}$ & $\begin{array}{r}\mathrm{CH}_{4} \text { not } \\
\text { recoverable } \\
{[\% \mathrm{~mol}]}\end{array}$ & $\begin{array}{r}\text { LBG } \\
{[\mathrm{kg} / \mathrm{h}]}\end{array}$ & $\begin{array}{r}\text { Specific } \\
\text { consumption } \\
{[\mathrm{kWh} / \mathrm{kg}]} \\
\end{array}$ & $\begin{array}{r}\text { Specific } \\
\text { production cost } \\
{[€ / \mathrm{kg}]}\end{array}$ \\
\hline Water scrubber & TP-L & 2 & 212.4 & 1.424 & 0.19 \\
\hline Organic scrubber & TP-L & 2 & 212.4 & 1.459 & 0.2 \\
\hline Chemical scrubber & TP-L & 1 & 214.5 & 2.277 & 0.31 \\
\hline PSA & TP-L & 2 & 212.4 & 1.424 & 0.19 \\
\hline Membrane & TP-L & 2 & 210.2 & 1.591 & 0.22 \\
\hline Traditional Cryogenic & TP-L & 0.3 & 216.1 & 3.282 & 0.45 \\
\hline Desublimation $^{(1)}$ & & 0 & 216.7 & 1.44 & 0.2 \\
\hline Novel cryogenic & & 0 & 216.7 & 1.297 & 0.18 \\
\hline
\end{tabular}

${ }^{(1)}$ Spitoni et al., 2017

The results show that the proposed novel cryogenic plant presents a specific energy consumption lower than all the other technologies and it is $1.297 \mathrm{kWh} \mathrm{kg}^{-1}$ of produced LBG. Compared with water scrubber or pressure swing adsorption, which represent the best available traditional technologies, the energy consumption and associated costs for $1 \mathrm{~kg}$ of produced LBG are $23.24 \%$ and $21.74 \%$ lower, respectively. This is mainly due to the fact that traditional technologies have a continuous consumption of energy, but also of involved materials and chemicals.

Figure 11 shows the total annual operating cost and revenues from selling the final products (LBG as vehicle fuel and also liquid $\mathrm{CO}_{2}$ for the novel cryogenic separation plant) obtained with the different above mentioned processes. As it can be seen, the novel cryogenic separation process allows the lowest operating costs and the highest revenues. The latter aspect is mainly due to the fact that a large amount of $\mathrm{L}-\mathrm{CO}_{2}$ is produced in this plant together with LBG. In fact, during the cryogenic separation process, an $\mathrm{L}^{-\mathrm{CO}_{2}}$ mass flow rate of $287 \mathrm{~kg}$ $\mathrm{h}^{-1}$ is recovered. Since the liquid carbon dioxide is $100 \%$ pure component, it can be sold to the food industry for a price of at least $0.5 € \mathrm{~kg}^{-1}$. This price is relatively high. However, even considering a lower wholesale trade price for liquid $\mathrm{CO}_{2}$ and halving it to $0.25 € \mathrm{~kg}^{-1}$, the revenues for the novel cryogenic separation system 
would decrease by $20 \%$, but the profit would remain higher than that of all the other traditional technologies. It is worth noting that investment costs are not taken into account in this evaluation, even if they play an important role because too high investment costs would prevent the diffusion of similar systems. This aspect is still under investigation and will be object of future evaluations.

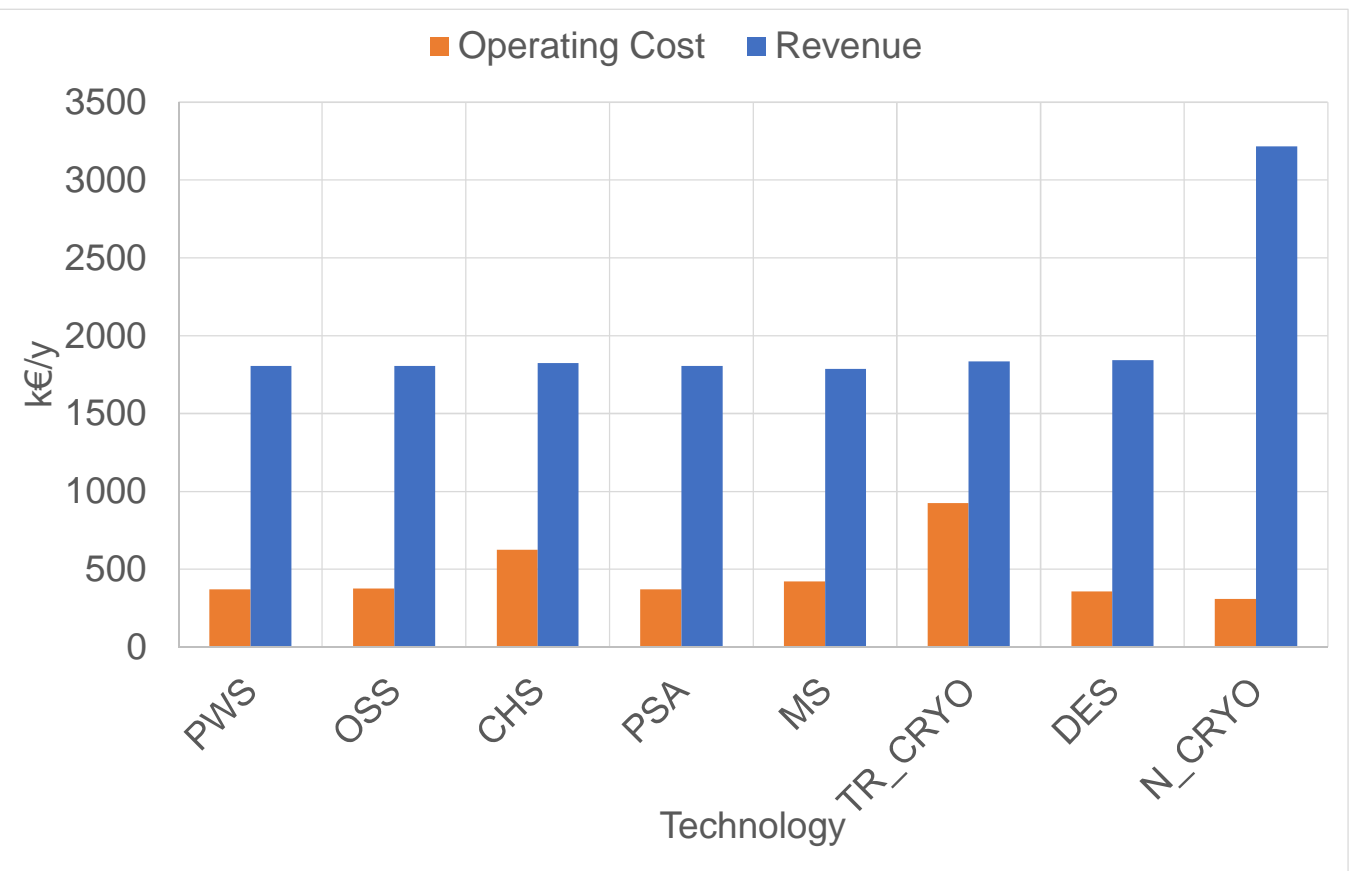

Figure 11. Yearly revenue and costs associated with the different technologies (assumed $8500 \mathrm{~h} / \mathrm{y}$ ). PWS: pressurized water scrubber; OSS: organic solvent scrubber; CHS: chemical scrubber PSA: pressure swing adsorption; MS: membrane separation; TR_CRYO: traditional cryogenic upgrading; DES: desublimation presented in Spitoni et al., 2017; N_CRYO: novel cryogenic separation.

\section{CONCLUSIONS}

Purpose of the present work is the evaluation of a novel cryogenic separation technology able to recover liquefied carbon dioxide, producing liquefied biogas at the same time. The proposed process has been evaluated and further optimized by means of a connection between modeFrontier ${ }^{\circledR}$, ESTECO and AspenHYSYS®, AspenTech software. The optimization procedure has been performed and the final optimum configuration has been found. The Evolutionary Strategy algorithm was found to be a good optimization procedure and a final specific energy consumption of $1.093 \mathrm{kWh} \mathrm{kg}^{-1}$ has been obtained. The post-processing of the optimization showed that the plant performances mainly depends on the $\mathrm{CO}_{2}$ content in inlet biogas (with a Pearson value of 0.877 and a factor value equal to 0.832 from the factor analysis). Therefore, a sensitivity analysis has been conducted by varying the $\mathrm{CO}_{2}$ content in inlet biogas for the optimum configuration of the plant. The analysis has shown that carbon dioxide concentration in inlet biogas strongly influences the overall performance of the plant, increasing specific energy consumption by $31 \%$ in the worst condition (i.e. $50 \% \mathrm{CO}_{2}$ content). However, since the liquefied carbon dioxide could be sold as a by-product for the food industry, the total revenue increases up to $5 \%$ with $50 \%$ of $\mathrm{CO}_{2}$ in inlet biogas. Eventually, specific energy consumption varies from $1.093 \mathrm{kWh} \mathrm{kg}^{-1}$ to $1.574 \mathrm{kWh} \mathrm{kg}^{-1}$ for a $\mathrm{CO}_{2}$ content in inlet biogas of $30 \%$ and 50\% respectively. A comparison between the novel technology and the state-of-the-art upgrading technologies is presented to better understand the economic feasibility of the process. The energy consumption and associated costs for $1 \mathrm{~kg}$ of produced LBG have been assessed to be, respectively, 23\% and 22\% lower 
than the cost for the best standard available alternative technology. Moreover, the importance of $\mathrm{L}_{-} \mathrm{CO}_{2}$ recovery, as a valuable by-product, has been highlighted.

\section{ACKNOWLEDGMENT}

The research leading to these results has received funding from the People Programme (Marie Curie Actions) of the European Union's Seventh Framework Programme FP7/2007-2013/ under REA grant agreement n³18908

\section{REFERENCES}

Arteconi, A., Spitoni, M., Polonara, F. 2015. The feasibility of liquid biogas (LBG) in Italy, Proceedings of the 24th International Congress of Refrigeration, Yokohama, Paper 0504.

Baccioli, A., Antonelli, M., Frigo, S., Desideri, U., Pasini, G., 2018. Small Scale bio-LNG plant: Comparison of Different Biogas Upgrading Techniques. App Energy, 217, 328-335.

Baena-Moreno, F.M., Rodríguez-Galán, M., Vega, F., Reina, T.R., Vilches, L.F., Navarrete, B., 2018. Regeneration of Sodium Hydroxide from a Biogas Upgrading Unit through the Synthesis of Precipitated Calcium Carbonate: An Experimental Influence Study of Reaction Parameters. Processes 6, 205.

Brendeløkken, H.W., 2016. Upgrading Technologies for Biogas Production Plants. Master's Thesis, The Arctic University of Norway.

Capodaglio, G. A., Callegari, A., Lopez, M. V., 2016. European Framework for the Diffusion of Biogas Uses: Emerging Technologies, Acceptance, Incentive Strategies, and Institutional-Regulatory Support. Sustain 8, 298.

Chang, H.-M., Chung, M.J., Park, S.B., 2009. Cryogenic Heat-Exchanger Design for Freeze-out Removal of Carbon Dioxide from Landfill Gas. J Therm. Sci. Tec., 4, 362-371.

Chutani, A., Rawat, P.S., Subrahmanyam, J.P., Pandey, R.K., 2005. Wear Characteristics of Biogas Based SI Engine During Repeated Starting and Stopping. Industrial Problems on Machines and Mechanisms (IPROMM), 24th - 25th February, I.I.T. Kharagpur, India.

Cryo Pur, 2018. Transforming biogas into bio-LNG and liquid bio- $\mathrm{CO}_{2}$. http://www.cryopur.com/en/technology/ (Accessed on 19/10/2018)

Faramawy, S., Zaki, T., Sakr, A.A.-E., 2016. Natural Gas Origin, Composition and Processing: A Review. J. Nat. Gas Sci. Eng. 34, 34-54.

Gao, T., Lin, W., Gu, A., Gu, M., 2010. Coalbed Methane Liquefaction adopting a Nitrogen Expansion Process with Propane Pre-Cooling. App. Energy 87, 2142-2147.

Hall, A.H., 1999. Correlation-based Feature Selection for Machine Learning. PhD Thesis, The University of Waikato, New Zealand.

Hakawati, R., Smyth, B.M., McCullough, G., De Rosa, F., Rooney, D., 2017. What is the most Energy Efficient Route for Biogas Utilization: Heat, Electricity or Transport? App. Energy, 206, 1076-1087. 
Hao, H., Wang, H., Ouyang, M., 2012. Fuel Consumption and Life Cycle GHG Emissions by China's onroad Trucks: Future Trends through 2050 and Evaluation of Mitigation Measures. Energy Policy 43, 244251.

He, Q.,Yu, G.,Yan, S., Dumée, L.F., Zhang, Y., Strezov, V., Zhao, S., 2018. Renewable CO2 absorbent for carbon capture and biogas upgrading by membrane contactor. Sep Pur Tech 194, 207-215.

Hveding, A.H., 2010. Production, Liquefaction and Transport of Low-Processed Natural Gas. Master's Thesis, Norwegian University of Science and Technology.

IEA, International Energy Agency, 2016. Energy and Air Pollution, World Energy Outlook Special Report.

IEA, International Energy Agency, 2017. $\mathrm{CO}_{2}$ emissions from fuel combustion.

Johansson, N., 2008. Production of Liquid Biogas, LBG, with Cryogenic and Conventional Upgrading Technology. Master's Thesis, Lunds Universitet.

Jonsson S., Westman J., 2011. Cryogenic Biogas Upgrading Using Plate Heat Exchangers. Master's Thesis, Department of Energy and Environment-Division of Energy Technology, Chalmers University of Technology.

Khan U.I., Othman D.H.M., Hashim H., Matsuura T., Ismail A.F., Arzhandi M.R.D., Azelee I.W., 2017. Biogas as a Renewable Energy Fuel - A Review of Biogas Upgrading, Utilization and Storage. Energy Conversion and Management 150: 227-294.

Lidkoping biogas, 2010. Biogas, the fuel of the future. http://www.lidkopingbiogas.se/ (Accessed on $19 / 10 / 2018)$

Maizonnasse, M., Plante, J.-S., Oh, D., Laflamme, C.B., 2013. Investigation of the Degradation of a LowCost Untreated Biogas Engine Using Preheated Biogas with Phase Separation for Electric Power Generation. Renew. Energy 55, 501-513.

Miltner, M., Makarur, A., Harasek, M., 2017. Review on available Biogas Upgrading Technologies and Innovations towards Advanced Solutions. J Clean Prod 161, 1329-1337.

Muñoz, R., Meier, L., Diaz, I., Jeison, D., 2015. A Review on the State-of-the-Art of Physical/Chemical and Biological Technologies for Biogas Upgrading. Rev Environ Sci Bio/Tech 14, 727-759.

Nachtmann, K., Baum, S., Fuchsz, M., Falk, O., 2017. Hofmann J. Efficient storage and mobile use of biogas as liquid biomethane. LANDTECHNIK 72, 179-201. DOI:10.15150/lt.2017.3163

Omar, B., Abou-Shan, R., El-Gammal, M., Fotidis, I.A., Kougias, P.G.,Zhanga, Y., Angelidakia, I. 2018. Simultaneous biogas upgrading and biochemicals production using anaerobic bacterial mixed cultures. Water 142, 86-95.

Pellegrini, L.A., De Guido, G., Langè, S., 2017. Biogas to Liquid Biomethane via Cryogenic Upgrading Tecnologies. Renew. Energy, 124, 75-83, http://dx.doi.org/10.1016/j.renene.2017.08.007

Pentair Haffmans, 2018. Haffmans Biogas upgrading technology. https://foodandbeverage.pentair.com/en/products/haffmans-biogas-upgrading-technology (Accessed on $19 / 10 / 2018)$

Riva, M., Campestrini, M., Toubassy, J., Clodic, D., Stringari, P., 2014. Solid-Liquid-Vapor Equilibrium Models for Cryogenic Biogas Upgrading. Ind Eng Chem Res 53, 17506-17514.

Schneidhofer, C., Sen, S., Dörr, N., 2011. Determination of the Impact of Biogas on the Engine Oil Condition Using a Sensor Based on Corrosiveness, Biofuel Production-Recent Developments and Prospects. Dr. Marco Aurelio Dos Santos Bernardes (Ed.), ISBN: 978-953-307-478-8, InTech, Available from: http://www.intechopen.com/books/biofuel-production-recent-developments-and- 
prospects/determination-ofthe-impact-of-biogas-on-the-engine-oil-condition-using-a-sensor-based-oncorrosiven

Shen, T., Gao, T., Lin, W., Gu, A., 2012. Determination of $\mathrm{CO}_{2}$ Solubility in Saturated Liquid $\mathrm{CH}_{4}+\mathrm{N}_{2}$ and $\mathrm{CH}_{4}+\mathrm{C}_{2} \mathrm{H}_{6}$ Mixtures above Atmospheric Pressure. J Chem Eng Data, 57, 2296-2303.

Spigarelli, F., Curran, L., Arteconi, A., 2016. China and Europe's Partnership for a more Sustainable World: Challenges and Opportunities. Bingley (UK): Emerald. ISBN 9781786353320.

Spitoni, M., Xiong, X., Arteconi, A., Polonara, F., Lin, W., 2017. Biogas Purification and Liquefaction by means of a Cryogenic Upgrading Technology. Refrigeration Science and Technology, 1st International Conference IIR of Cryogenics and Refrigeration Technology, pp. 107-115, 22-25 June 2016, Bucharest.

Statistisches Bundesamt, DESTATIS, 2018. Data on Energy Price Trends. Available on: https://www.destatis.de/DE/Publikationen/Thematisch/Preise/Energiepreise/EnergyPriceTrendsPDF_561 9002.pdf? blob=publicationFile

Sun, Q., Li, H., Yan, J., Liu, L., Yu, Z., Yu, X., 2015. Selection of Appropriate Biogas Upgrading Technology - A Review of Biogas Cleaning, Upgrading and Utilization. Renew Sustain Energy Rev, 51, 521-532.

Tan, Y., Nookuea, W., Li, H., Thorin, E., Yan, J., 2017. Cryogenic Technology for Biogas Upgrading Combined with Carbon Capture - A Review of Systems and Property Impact. Energy Procedia 142: 37413746.

Tharän, D. et al. (2014). Biomethane - Status and Factors Affecting Market Development and Trade. IEA Task 40 and Task 37 Joint Study.

Xiong, X., Lin, W., Gu, A., 2015. Integration of $\mathrm{CO}_{2}$ Cryogenic Removal with a Natural Gas Pressurized Liquefaction Process using Gas Expansion Refrigeration. Energy 93, 1-9.

Yoo, Y. B., 2017. Economic Assessment of Liquefied Natural Gas (LNG) as a Marine Fuel for $\mathrm{CO}_{2}$ Carries Compared to Marine Gas Oil (MGO). Energy 121, 772-780.

Yousef, A.M., Eldrainy, Y.A., Maghlany, W.M., Attia, A., 2017. Biogas Upgrading Process via LowTemperature $\mathrm{CO}_{2}$ Liquefaction and Separation. J Nat Gas Sci Eng 45, 812-824.

Yuan, Z., Cui, M., Xie, Y., Li, C., 2014. Design and Analysis of a Small-Scale Natural Gas Liquefaction Process adopting Single Nitrogen Expansion with Carbon Dioxide Pre-Cooling. App Therm Eng 64, 139146.

Zhang, L., Burgass, R., Chapoy, A., Thoidi, B., Solbraa, E., 2011. Measurement and Modeling of $\mathrm{CO}_{2}$ Frost Point in the $\mathrm{CO}_{2}-$ Methane Systems. J Chem. Eng. Data 56, 2971-2975. 